\title{
INOVAÇÕES METODOLÓGICAS NA FORMAÇÃO INICIAL E PERMANENTE DE PROFESSORES
}

\author{
INNOVACIONES METODOLÓGICAS EN LA FORMACIÓN INICIAL Y \\ PERMANENTE DE DOCENTES
}

\author{
METHODOLOGICAL INNOVATIONS IN THE INITIAL AND PERMANENT \\ FORMATION OF TEACHERS
}

\author{
Maria Elizete Pereira Alencar OLIVEIRA ${ }^{1}$ \\ Maria Cleide da Silva BARROSO ${ }^{2}$ \\ Ciro Mesquita de OLIVEIRA ${ }^{3}$
}

RESUMO: O presente estudo mostra registros que os professores fazem sobre suas práticas, vivências diante do impacto das mudanças na política educacional. O interesse por refletir sobre o ideário dos docentes iniciou a partir de uma nova práxis em que um dos entraves da aprendizagem dos alunos está relacionado aos precários conhecimentos acadêmicos do professor, com discrepâncias entre teoria e prática, visto que a teoria é importante, mas sozinha é insuficiente para a sala de aula. O objetivo do estudo foi investigar, através da literatura, a necessidade de alinhamento entre teoria e prática. Os procedimentos metodológicos utilizados para a coleta de dados incluíram revisão da literatura, observação in loco e entrevistas semiestruturadas aos docentes. As informações coletadas foram analisadas qualitativamente, sob a ótica dos autores que orientaram a fundamentação teórica. Concluiu-se que compete ao educador perceber características do discente e sua interação com o ambiente.

PALAVRAS-CHAVE: Inovações metodológicas. Prática pedagógica. Teoria e prática.

RESUMEN: Este estudio muestra registros que hacen los docentes sobre sus prácticas, experiencias ante el impacto de los cambios en la política educativa. El interés por conocer lo que piensan los docentes sobre su práctica se inició con una reflexión dirigida a una nueva praxis en la que uno de los obstáculos para el aprendizaje de los estudiantes está relacionado con el precario conocimiento académico del docente, con discrepancias entre la teoría y la práctica, ya que la teoría es importante, pero por sí solo es insuficiente para el aula. El objetivo del estudio fue explorar, a través de la literatura, la necesidad de alinear la teoría y la práctica. Los procedimientos metodológicos utilizados para la recolección de datos incluyeron revisión de literatura, observación in situ y entrevistas semiestructuradas con maestros. La información recolectada fue analizada cualitativamente, desde la perspectiva de los autores que orientaron

\footnotetext{
${ }^{1}$ Instituto Federal de Educação, Ciência e Tecnologia do Ceará (IFCE), Fortaleza - CE - Brasil. Mestranda no Programa de Pós-Graduação em Ensino de Ciências e Matemática. ORCID: https://orcid.org/0000-0002-33161711. E-mail: elizaalencar1@yahoo.com.br

${ }^{2}$ Instituto Federal de Educação, Ciência e Tecnologia do Ceará (IFCE), Fortaleza - CE - Brasil. Professora do Programa de Pós-graduação em Ensino de Ciências e Matemática. Doutorado em Educação (UFC). ORCID: https://orcid.org/0000-0001-5577-9523. E-mail: ccleideifcemaraca@gmail.com

${ }^{3}$ Universidade Estadual do Ceará (UECE), Fortaleza - CE - Brasil. Doutorando no Programa de Pós-graduação em Educação (UECE). Mestrado em Educação (UECE). ORCID: https://orcid.org/0000-0002-2463-664X. E-mail: ciro.mesquita16@gmail.com
} 
el fundamento teórico. Se concluyó que corresponde al educador percibir las características del alumno y su interacción con el entorno.

PALABRAS CLAVE: Innovaciones metodológicas. Práctica pedagógica. Teoría y práctica.

ABSTRACT: This study shows records that teachers make about their practices, experiences considering the impact of changes in educational policy. The interest in knowing what teachers think about their practice began with a reflection aimed at a new praxis in which one of the obstacles to student learning is related to the teacher's precarious academic knowledge, with discrepancies between theory and practice, since theory is important, but alone it is insufficient for the classroom. The aim of the study was to explore, through the literature, the need for alignment between theory and practice. The methodological procedures used for data collection included literature review, on-site observation, and semi-structured interviews with teachers. The information collected was analyzed qualitatively, from the perspective of the authors who guided the theoretical foundation. It was concluded that it is up to the educator to perceive characteristics of the student and their interaction with the environment.

KEYWORDS: Methodological innovations. Pedagogical practice. Theory and practice.

\section{Introdução}

A presente pesquisa tomou como base uma análise das inovações metodológicas voltadas à formação de professores, tanto inicial como permanente, e seus registros, na tentativa de compreender suas vivências diante do impacto das mudanças na política educacional, em confronto com suas necessidades e possibilidades educacionais que devem ser constantemente aprimoradas na formação continuada.

Muitos professores têm buscado essas formações com o intuito de alcançarem a ascensão profissional e viabilizar a compreensão da sua prática profissional. Emerge desse contexto o problema de que trata esta pesquisa que suscita alguns questionamentos: Essas formações estão preparando os profissionais da educação para se tornarem professores reflexivos e pesquisadores? Os educadores têm aproveitado esses estudos para a ressignificação das suas práticas e o direcionamento do seu trabalho com vistas a contribuir com a melhoria do ofício docente? A formação do professor reflexivo e pesquisador constitui um referencial sobre a prática do docente?

Em busca de responder a essas indagações, procurou-se conduzir o mestre a iniciar uma reflexão voltada para as inovações vivenciadas em sala e, dessa forma, melhorar sua compreensão sobre a prática docente, os entraves e perspectivas, a partir da leitura de obras apresentadas no corpo do texto. 
O referencial teórico utilizado contemplou contribuições de autores que traduzem ideias atuais sobre a redefinição da prática docente. Daí sua relevância, pois poderá contribuir com o debate na área de ensino e apontar atuais caminhos de formação, mais condizente com a realidade.

Percebe-se que alguns professores que atuam nos anos iniciais não possuem experiência, tornando suas aulas monótonas e cansativas, o que compromete a aprendizagem dos estudantes (CHARLOT, 2006). A intenção de compreender o papel da formação continuada na prática do professor partiu do interesse por aprofundar os conhecimentos sobre essa temática junto aos alunos, tanto no aspecto teórico como no prático.

Diante desse cenário, considera-se que um dos entraves da aprendizagem dos educandos está relacionado à instrução acadêmica do professor, que é notadamente fragmentada, com a teoria muitas vezes desarticulada da prática. Entende-se, portanto, que a teoria é muito importante, mas sozinha é insuficiente para a realidade da sala de aula.

A pesquisa aqui apresentada teve como objetivo principal investigar, através de dados da literatura, se a teoria e a prática dos professores, sobretudo daqueles que lecionam nas séries iniciais, estão sendo orientados e direcionados para uma relação teoria prática satisfatória e exitosa nos cursos de formação docente. Nessa perspectiva, os seguintes objetivos específicos foram delineados: i. Compreender a relação dos professores com os saberes que são construídos por eles e avaliados como válidos para a sua prática pedagógica; ii. Analisar a mobilização apresentada pelos professores em suas práticas frente às inúmeras dificuldades que enfrentam na rotina escolar.

Neste trabalho, discorre-se sobre o entendimento - ideário - dos docentes das séries iniciais do Ensino Fundamental sobre suas práxis. Nas análises, eles apontaram ocasiões que propiciaram conhecimentos concernentes ao ato docente, tencionando a efetivação de ações pedagógicas ousadas, representando intencionalidade e sistematização com vistas ao progresso dos alunos, tendo os responsáveis das escolas como aliados da pesquisa.

Diante do exposto, a relevância deste estudo reside no fato de ser um canal, no sentido didático, para o diálogo acadêmico sobre as iniciativas de formação inicial e continuada de professores, uma vez que possibilita repensar a sua prática, bem como o aprimoramento da formação, colaborando com a melhoria da qualidade de ensino.

Complementando os requisitos para a efetivação da pesquisa, se submeteu ao Conselho de Ética e Pesquisa - CEP, do Instituto Federal de Educação, Ciência e Tecnologia do Ceará IFCE, onde está abrigado o Programa de Pós - Graduação em Ensino de Ciências e Matemática - PGECM, o qual a autora principal realizou a pesquisa, sob o CAAE n ${ }^{\circ}$ 40367120.5.0000.5589. 
Este estudo justifica-se, portanto, pela necessidade de fornecer uma leitura atualizada sobre o contexto escolar, de forma a direcionar práticas pedagógicas eficientes voltadas à formação humana. A conveniência da reflexão sobre a práxis docente é, portanto, uma sugestão para enriquecer o debate acerca do ato pedagógico, proporcionando, assim, a sua reavaliação, auxiliando o ensino continuado dos educadores e estimulando o pleno desenvolvimento dos alunos das séries iniciais do Ensino Fundamental.

\section{Referencial teórico}

As transformações aceleradas no meio social reclamam a atuação de professores críticos e reflexivos. A sociedade vive um momento de profundas mudanças na educação e, para responder a essa realidade, é preciso motivar a formação inicial e continuada dos professores para gerar uma motivação intrínseca relacionada às tarefas.

No final do século XX presenciaram-se grandes transformações tanto no campo socioeconômico e político quanto no da cultura, da ciência e da tecnologia. Ocorreram grandes movimentos sociais, como aqueles no leste europeu, no final dos anos de 1980, culminando com a queda do Muro de Berlim. Ainda não se tem a ideia clara dos impactos gerados pela 'globalização' capitalista da economia, das comunicações e da cultura e as modificações tecnológicas que tornaram possível o surgimento da 'era da informação' (GADOTTI, 2000).

Tendo em vista os aspectos discutidos, foram consultados alguns teóricos que abordam essa temática como uma prática inovadora, dialógica, que deve favorecer uma tomada de consciência pelos professores e, consequentemente, a aprendizagem dos educandos.

Por muitos anos, o professor foi visto como um propagador de abstrações incontestadas, como um especialista cuja responsabilidade era apenas transferir conhecimentos aos seus alunos, sem se voltar para o desenvolvimento de habilidades práticas, não contribuindo, assim, para o avanço da aprendizagem eficiente dos discentes(SCHÕN, 2000).

Nesta perspectiva,

[...] é possível através da observação e da reflexão sobre nossas ações, fazermos uma descrição do saber tácito que está implícito nelas. Nossas descrições serão de diferentes tipos, dependendo de nossos propósitos e das linguagens disponíveis para essas descrições. Podemos fazer referência, por exemplo, às sequências de operações e procedimentos que executamos; aos indícios que observamos e às regras que seguimos; ou os valores, às estratégias e aos pressupostos que formam nossas teorias da ação (SCHÖN, 2000, p. 31).

Salienta-se, então, a relevância da produção de uma prática ponderativa que propicie a 
reelaboração de concepções, a validação de conhecimentos e que viabilize a atuação crítica do educador, bem como uma postura participante do educando, desfazendo o conceito de que o docente é um mero transferidor, refazendo sua identidade enquanto profissional. E essa alteração, de fato, só será viável se estiver clara, nessa ação, a reflexão crítica sobre a própria prática. Argumenta-se, portanto, que embora já ocorra um acentuado número de pesquisas sobre as práticas de ensino nos anos iniciais, ainda se percebe algumas carências como a falta de preparação adequada dos responsáveis que atuam nesta área (CONTRERAS, 2002).

Em se tratando de prática educativa, trazendo para o debate uma construção crítica da realidade e de transformação social, captam-se também os fundamentos filosóficos sobre práxis. Nesse sentido, empresta-se o conceito vazqueano sobre práxis, no qual apresenta a "categoria central da filosofia que se concebe ela mesma não só como interpretação do mundo, mas também como guia de sua transformação" (VÁZQUEZ, 2007, p. 6).

Ademais, compreende-se a práxis transformadora como produto e expressão da realidade, das necessidades geradas pelo conhecimento, e das ações dos sujeitos.

Diante do quadro aqui apresentado, concordamos que

[...] é relativamente consensual, nessas pesquisas, o diagnóstico relativo à baixa qualidade de ensino, quanto à ineficácia das estratégias metodológicas adotadas e, principalmente, sobre o 'precário' conhecimento de conteúdo apresentado pelos professores (LIMA; MAUÉS, 2006, p. 164).

Para um melhor entendimento, procurou-se aqui evidenciar os princípios do exercício pedagógico, com a intenção de apresentar, no presente trabalho, o discurso do professor crítico e reflexivo. É oportuno, então, enxergar nitidamente o que seria a prática pedagógica e discutir a respeito do conceito de uma atitude critico reflexiva do professor.

Essas ponderações foram embasadas nas contribuições de Vásquez (2007), articuladas acima, e nas contribuições de Veiga (2008), que se volta à parte pedagógica pontuando as contribuições da teoria e da própria prática.

É preciso, entretanto, deixar claro que a ação pedagógica do professor necessita, em síntese, do entendimento que ele tem a respeito do seu próprio trabalho. O docente deve ser capaz de fortalecer uma rotina que seja renovadora, considerável, adequada ao meio social dos estudantes, pois, ao contrário, será capaz de mostrar uma realidade mecânica, que tem como principal fim transferir conteúdos e realizar atividades meramente repetitivas.

Destaca-se que a práxis sempre se beneficia com os conhecimentos teóricos, o que é corroborado por Vásquez, ao afirmar que "a teoria vem fundamentar a prática” (VÁSQUEZ, 2007, p. 243). Assim, existe uma reciprocidade entre ambas, porquanto uma contribui com o 
desenvolvimento da outra. Sobre isso, apresentamos a concepção que defendemos, ressaltando a relação do lado teórico com o lado prático, da seguinte forma:

[...] o lado objetivo da prática pedagógica é constituído pelo conjunto de meios, o modo pelo qual as teorias pedagógicas são colocadas em ação pelo professor. O que as distingue da teoria é o caráter real, objetivo, da matériaprima sobre a qual ela atua, dos meios ou instrumentos com que se exerce a ação, e de seu resultado ou produto. Sua finalidade é a transformação real, objetiva de modo natural ou social, satisfazer determinada atividade humana (VEIGA, 2008, p. 17).

Deve-se, portanto, mencionar que, lamentavelmente, diante dos obstáculos que são diariamente encontrados no dia a dia, bem como no próprio sistema de ensino, o docente se vê, cada vez mais, distanciado dessas mudanças, que são importantes para uma melhor execução de sua prática pedagógica. Isso ocorre, certamente, porque muitos cursos de formação apresentam um conhecimento teórico dissociado da prática que, em muitos momentos terminam não beneficiando a pesquisa e o próprio processo formativo, o que impede sua transformação.

Dessa forma, é relevante que o educador reconheça essa concepção e que colabore com a construção de ações desenvolvidas como tais. Considera-se, ainda, que o sistema de ensino atual, sobretudo o público, acaba por não oferecer todas as condições necessárias ao progresso e à melhoria que carece de tempo e dedicação, o que falta a muitos professores. A atividade docente é diária, uma composição pessoal e profissional que não chega ao fim, pois o educador precisa constantemente de novos saberes.

O mestre precisa, portanto, ser capaz de refazer continuamente sua ação pedagógica e, para isso, é necessário que ele seja estimulado a investigar e ser capaz de modificar seu exercício em um ato que seja, de fato, transformador e possibilite aos alunos mergulharem em um espaço de aprendizagem que disponha de conhecimentos apropriados e expressivos.

É oportuno ressaltar o argumento necessário ao desempenho pedagógico, para que se possa alcançar um entendimento claro sobre o ato desenvolvido por cada professor em sala de aula, para que ele possa, a partir de então, pautar seu trabalho de maneira critico reflexiva. Nesse sentido, ele deve observar-se, e refletir sobre as necessidades apresentadas e olhar para si mesmo com um exame de consciência franco e, acima de tudo, instrutivo a respeito de sua práxis, para que, de fato, ele possa vivenciar uma provável melhoria dos resultados do seu trabalho.

Admite-se, portanto, que a reflexão é imprescindível ao exercício da docência, confirmando que a definição de prática pedagógica deve ser continuamente questionada pelo 
professor, a fim de proporcionar a conquista de um novo caminho para aperfeiçoar a atividade por ele desenvolvida. É relevante, então, indicar que a "[...] prática reflexiva nos remete a dois processos mentais que devemos distinguir, principalmente se considerarmos seus" (PERRENOUD, 2002, p. 30).

É preciso crer que o educador, a partir da análise da sua atividade, pode aperfeiçoar seu ofício e proporcionar uma melhor aprendizagem aos seus alunos. Isso configura a ideia de que o entendimento gerado através do questionamento da própria prática pode levar o professor a refazer seu trabalho, a partir de mudanças que propiciem alterações autênticas, que viabilizarão uma melhor qualidade do seu ensino.

Nesse contexto, a postura do professor se caracteriza como ponto alto no somatório entre o que se quer e o que se pode fazer para transformar atitudes e vidas através do ato de educar. Ainda, atribui-se ao aluno a tarefa de construir um futuro melhor, mas a atuação do núcleo gestor junto à prática do docente é o ponto de partida para que, em parte, isso se concretize.

O professor precisa refletir permanentemente sobre sua conduta, que deve instigar os sujeitos aprendizes a construírem variados pontos de vista, para obter uma noção contextualizada do mundo em que vive. Concordamos com a afirmação a seguir:

[...] que o saber docente não é formado apenas da prática sendo também nutrido pelas teorias da educação. Dessa forma, a teoria tem importância fundamental na formação dos docentes, pois dota os sujeitos de variados pontos de vista para uma ação contextualizada, oferecendo perspectivas de análise para que os professores compreendam os contextos históricos, sociais, culturais, organizacionais e de si próprios como profissionais (PIMENTA, 2000, p. 24).

O aluno não deve se limitar ao conteúdo repassado em sala de aula, pois ele deve ter um espírito investigativo, ir além, buscando novos conhecimentos, tentando observar o que foi visto em teoria. Nessa perspectiva, deve-se explicitar uma crítica contra a educação bancária, assim definida por Paulo Freire (1998) como uma abordagem em que um manda e o outro obedece em que o professor se imagina o único dono do saber e o aluno um mero aprendiz, concepção de educação que se mostra, nitidamente, como um instrumento da opressão.

Por essa nova concepção de estudante como sujeito de direitos, ele passa a ser considerado um ser em harmonia com a história, que está permanentemente em desenvolvimento. Logo, o professor que deve atuar nesse cenário de mudanças precisa que incorpore a figura do interlocutor, daquele que ouve o aluno, aponta-lhe os caminhos e que proporcione uma ambiência na qual se possa desenvolver uma relação mútua de igualdade de aprendizagens. 
No que diz respeito à formação de professores, no Brasil há de fato uma tradição na definição do pedagogo como alguém que ensina algo. Essa concepção veio desde a década de 1930 com a ideia de que pedagogo é o profissional que vai ensinar nas séries iniciais, não se pode reduzir a educação ao ensino, nem aos métodos de ensino (GIMENES, 2012).

Diante do que se analisou, constatou-se que a instrução do professor se caracteriza como o ponto alto na somatória entre o 'o que se quer e o que se pode fazer' para transformar atitudes e vidas através do ato de educar. Atribui-se ao aluno a tarefa de contribuir para um futuro melhor, mas essa instrução do professor é o ponto focal para que, em parte, isso se concretize. Entretanto, os cursos de formação das Universidades não têm dado conta, adequadamente, do desenvolvimento acadêmico. O ideal seria que as propostas desenvolvidas se voltassem para os saberes que os professores utilizam em seu cotidiano, demarcando que não se trata de puro praticismo, porém uma escolha entre alternativas apontando para uma experiência exitosa (PIMENTA, 2002).

A realidade da educação na atualidade é o reflexo de assuntos discutidos no passado. As famílias pediam aos educadores especializados para isentá-las do cuidado na formação de seus filhos, ou seja, que transformasse seus filhos (indisciplinados) em sujeitos ajuizados, polidos, instruídos, senhores de si. Aspiravam a livrar-se de uma tarefa, a alguém que trabalhasse sistemática e metodicamente (PAULON, 2007).

Ter conhecimentos e 'saber fazer' são as qualidades indispensáveis ao educador, que o caracterizam e o distinguem. Ele é o único a quem todas essas características são necessárias, desde quando a pedagogia nasceu. Conhecimento e ação são, portanto, dois aspectos inseparáveis da atividade humana. O conhecimento não é mera contemplação, nem a prática mera atividade. Não há, pois, autêntico conhecimento e autêntica ação, se não se expressam numa permanente interrelação unitária.

É preciso atentar para os saberes da docência e entre eles a questão da formação docente. Inácui Filho (2003) afirma que as disciplinas pedagógicas estão de tais formas desacreditadas, que os alunos das licenciaturas preferem estudar o conteúdo da parte específica.

É preocupante formar professores, gestores e pesquisadores em um curso com aspectos formadores limitados. Corre-se o risco de promover cursos aligeirados e alijados dos saberes necessários à prática. É naturalmente necessária para o ensino fundamental uma configuração em nível superior específica de primeira à quarta série, devido ao currículo precisar dominar conhecimentos e metodologias de campos muito diferentes, como: português, matemática, história, geografia, ciências. 


\section{Contornos metodológicos}

A pesquisa consiste em buscar respostas concernentes as inovações metodológicas relacionadas ao atual contexto da formação inicial e permanente de professores. Tentando adequar essa pratica já existente em outra realidade.

Buscando compreender melhor o que os professores pensam sobre as inovações metodológicas e as demais questões que circundam essa área do ensino, realizou-se a aplicação de questionários com quatro professores que atuam nos anos iniciais do ensino fundamental. As respostas serão apresentadas, juntamente com a discussão teórica, a seguir.

Os questionários, como já pontuado aqui, foram enviados aos e-mails dos professores, com prazo de 30 dias para respostas. Ao fim desse prazo, os quatro professores retornaram o questionário respondido.

As respostas foram então tabuladas, facilitando a análise dos dados obtidos. Foi realizada uma primeira leitura das respostas dadas, pontuando aspectos que pudessem se apresentar como relevantes para a presente pesquisa. A segunda leitura, mais atenta, teve a finalidade de elencar categorias que ajudassem na análise das respostas. A terceira leitura objetivou separar, a partir das categorias catalogadas, as proximidades ou similaridades das respostas dadas, bem como os distanciamentos ou diferenças encontradas.

O questionário apresentou as seguintes perguntas:

1) Considerando o contexto social, o conhecimento escolar tem grande importância para preparar o aluno para a vida, desta maneira, podemos qualificar a disciplina de ciências como uma ferramenta social que possibilita uma abrangência que passa por disciplina qualificada em avaliações externas? Explique sua resposta

2) Na conjectura atual com desafios ambientais tão exacerbados, a avaliação feita nas escolas, com relação à disciplina de ciências contempla as expectativas que são mencionadas na BNCC?

3) No mundo contemporâneo preocupar-se com a alfabetização científica não seria uma forma de inserir a disciplina nas avaliações externas? Justifique.

No presente trabalho, descreveu-se sobre a formação de professores, analisando o sentido que eles precisam dar a sua prática, posicionando-se sobre ela. A observação participante e a entrevista semiestruturada foram os procedimentos utilizados na coleta de 
dados, em busca de detectar alguns pontos relevantes para esta pesquisa que foram submetidos a uma análise qualitativa, à luz das opiniões dos autores consultados na revisão bibliográfica.

Nessa perspectiva, a pesquisa qualitativa, segundo Bogdan e Biklen (1994), não exime o pesquisador de se envolver com os pesquisados. As relações e as experiências que unem todos os atores da pesquisa são fortes e imprevisíveis, na medida em que se busca compreender o universo vivenciado por cada um deles. Contudo, entende-se que as identidades concretizadas nas pessoas do pesquisador e dos pesquisados podem permanecer bem definidas se eles se reconhecem mutuamente, cada um em sua condição.

\section{Resultados da pesquisa com os professores}

Considerando que a educação escolar apresenta progressos, especialmente pela expansão do Ensino Fundamental, é indispensável assegurar a aprendizagem dos educandos. Nessa visão, a formação de professores aponta indicativos que têm que ser levados em consideração para novos segmentos e intervenções. Não obstante, faz-se necessário olhar para a instrução dos professores como uma ação mediadora, de construção e renovação.

Nesse desdobramento, a capacitação permanente dos professores pode contribuir com a melhoria da prática educativa, uma vez que pode ser utilizada como uma ferramenta que auxilie a transformação de sua prática voltada à aprendizagem dos alunos. Logo, um dos grandes desafios do cotidiano dos educadores é a aplicação de saberes relacionando-os à prática em sala de aula e aos saberes construídos pelos alunos na sua vivência cotidiana. Contudo, é preciso levar o discente à compreensão da necessidade de mudar sua postura, a partir das atuais teorias aplicadas nos cursos de formação inicial, e isso não é algo fácil.

É evidente, portanto, a necessidade de articular teoria e prática em um novo modelo emergente de estudo, visto que as transformações aceleradas ocorridas na sociedade reclamam uma instrução de professores críticos e reflexivos, em que o conhecimento teórico esteja associado à prática vivenciada na sala de aula, antevendo as transformações necessárias e instrumentalizando-se para nela intervir, é um pressuposto básico.

Pelas respostas dos professores às entrevistas, constatou-se que é de elevada importância uma reavaliação da prática pedagógica, a começar pelo conceito de reflexão como uma ferramenta que indicará o exercício do professor e irá proporcionar a tomada de um novo posicionamento frente às dificuldades enfrentadas, validando assim, a aquisição de habilidades significativas para os dois atores da sala de aula: professor e aluno.

No momento em que surgirem professores críticos e reflexivos, a prática educativa 
melhorará consideravelmente, no sentido de encontrar soluções para os problemas enfrentados em sala de aula, levando o ensino a alcançar resultados mais significativos. No entanto, devese destacar que, na busca de alcançar uma efetiva transformação nas formas de ensinar, existe a possibilidade de o docente não alcançar as metas que direcionam essa mudança. Ressalta-se, então, ser indispensável que os professores sejam bem preparados e definam os caminhos para atingir os objetivos educacionais esperados.

É importante que o mestre se qualifique para a vivência pedagógica. Para isso, deve ser motivado a buscar a superação de todas as adversidades impostas pela realidade, ultrapassando todos os obstáculos e construindo uma nova prática através de novos saberes. A motivação do professor deve ser influenciada pela sala de aula, que é o seu laboratório.

A posição motivacional do professor é algo que pode sofrer impactos devido a fatores sociocontextuais como o número de alunos em sala de aula, o tempo de experiência no magistério, as interações com a gestão, entre outros.

Quando há um relacionamento de troca com o aluno, o professor sai da sua rotina solitária para vislumbrar toda a repercussão que sua prática pode trazer ao estudante. Esse, portanto, é um dos motivos que o leva a valorizar o ensino e, dessa forma, começar a investir em projetos para aperfeiçoar seu ofício.

\section{Considerações finais}

Procurou-se, na elaboração deste trabalho, aguçar o olhar sobre todos os detalhes que pudessem fornecer informações mais próximas do pensamento dos professores, para não padronizar concepções. A pandemia atualmente vivenciada devido à Covid-19 obrigou o isolamento social para evitar a disseminação do vírus causador, Sars-Cov-2. Assim, a pesquisa desviou-se do campo de observação, mas isso não impossibilitou a finalização da pesquisa, nem tampouco interrompeu o seu processo, exigindo, entretanto, um novo momento de estudo.

A elaboração da escrita deste artigo esteve baseada nos dados que a observação da prática dos professores revelou e na interpretação das informações recolhidas a partir das reflexões dos professores sobre as suas práticas, expressas nas entrevistas. Por conseguinte, o que aqui foi apresentado contém os relatos dos professores e suas análises e interpretações descritas em confronto com o pensamento dos autores consultados na revisão da literatura, estabelecendo relações entre elas, o que caracterizou uma abordagem qualitativa.

Um ponto a ser evidenciado é o posicionamento dos professores sobre sua formação que não associou a teoria à prática a ser desenvolvida em sala de aula e não incentivou a realização 
do ensino e da aprendizagem a partir do diálogo entre o professor e o aluno, que é essencial à troca de saberes específicos e ocupa lugar importante.

O cotidiano do educador é complexo e desafiador e estabelecer uma rotina para lidar com ele é uma tarefa bastante exigente e difícil. Alguns dos aspectos que devem ser levados em consideração nesse contexto é o registro das aprendizagens efetivadas pelos estudantes e sua avaliação. Determinados aspectos que fazem parte do cotidiano do educador podem influenciar de maneira significativa no desenvolvimento dos estudantes. Muitas vezes, esses aspectos se constituem práticas pouco discutidas.

Essas práticas devem funcionar como estratégias que chamem a atenção dos alunos e esse seria um cuidado que o educador poderia exercitar para realizar um bom trabalho em sala, tendo como consequência a interação dos alunos, a socialização e o desenvolvimento da autonomia, resultando um bom rendimento de aprendizagens.

Constatou-se que compete ao educador perceber quais são as características de cada aluno, seu jeito de ser e de se relacionar com o ambiente que passa a frequentar, bem como a maneira como interage com seus colegas e com as pessoas que dela cuidam e que a educam. É preciso, portanto, respeitar o ritmo de cada discente, bem como suas manifestações e considerar suas aprendizagens prévias, construídas no ambiente em que vivem.

Espera-se que este estudo proporcione boas referências sobre a prática pedagógica crítico-reflexiva e sirva como alicerce para outras pesquisas que busquem entender o aprimoramento dos conhecimentos e da prática do professor, tão indispensáveis ao aprendizado, como um importante instrumento de mudança. A análise crítica produzida por esta pesquisa acadêmica sobre a formação de professores, brevemente exposta, colocou em evidência a necessidade de ações no interior das salas de aula e suas determinações pelo sistema escolar.

\section{REFERÊNCIAS}

BOGDAN, R.; BIKLEN, S. Investigação qualitativa em educação. Porto: Porto Editora, 1994.

CHARLOT, B. Fala mestre. Nova Escola, n. 196, p. 15-18, out. 2006.

CONTRERAS, J. Autonomia dos professores. São Paulo: Cortez, 2002.

FREIRE, P. Pedagogia do oprimido. São Paulo: Paz e Terra, 1998.

GADOTTI, M. Perspectivas atuais da educação. Perspectiva, São Paulo, v. 14, n. 2, p. 3-11, jun. 2000. DOI: https://doi.org/10.1590/S0102-88392000000200002 
GIMENES, N. Formação de professores para a educação infantil, anos iniciais do ensino fundamental e os cursos de Pedagogia: novos e velhos desafios. Educação, São Paulo, 12 dez. 2013. Disponível em: https://revistaeducacao.com.br/2013/12/12/formacao-deprofessores-para-a-educacao-infantil-anos-iniciais-do-ensino-fundamental-e-os-cursos-depedagogia-novos-e-velhos-desafios/. Acesso em: 21 out. 2021.

INÁCUI FILHO, G. A Monografia na Universidade. 6. ed. Campinas, SP: Papirus, 2003.

LIMA, M.E.C.C.; MAUÉS, E. Uma releitura do papel da professora das séries iniciais no desenvolvimento e aprendizagem de ciências para crianças. Revista Ensaio, Belo Horizonte, v. 8, n. 2, p.184-198, jul./dez. 2006. Disponível em: https://bityli.com/IeKxr. Acesso em: 15 jan. 2021.

PAULON, S. M. (org.) Documento Subsidiário à política de inclusão. 2. ed. Ministério da Educação. Secretaria de Educação. Brasília: 2007.

PERRENOUD, P. A prática reflexiva no ofício do professor: profissionalização e razão pedagógica. Porto Alegre, RS: Artmed, 2002.

PIMENTA, S.G. A prática (e a teoria) docente ressignificando a didática. In: OLIVEIRA, M. R. N. (Org). Confluências e divergências entre didática e currículo. Campinas, SP: Papirus, 2000.

PIMENTA, S. G.; GHEDIN, E. (Org). Professor Reflexivo no Brasil: gênese e crítica de um conceito. São Paulo: Cortez, 2002

SCHÖN, D. Educando o profissional reflexivo: um novo design para o ensino e a aprendizagem. Porto Alegre, RS: Artmed, 2000.

VÁSQUEZ, A. S. Filosofia da práxis. São Paulo: Expressão Popular, 2007.

VEIGA, I. P. A. A prática pedagógica do professor de didática. 11. ed. Campinas, RS: Papirus, 2008. 


\section{Como referenciar este artigo}

OLIVEIRA, M. E. P. A.; BARROSO, M. C. S.; OLIVEIRA, C. M. Inovações metodológicas na formação inicial e permanente de professores. Revista on line de Política e Gestão Educacional, Araraquara, v. 25, n. 3, p. 2326-2339, set./dez. 2021. e-ISSN:1519-9029. DOI: https://doi.org/10.22633/rpge.v25i3.15313

Submetido em: 13/09/2021

Revisões requeridas em: 16/10/2021

Aprovado em: $14 / 11 / 2021$

Publicado em: 08/12/2021 